\title{
Molecular Epidemiology of Plum pox virus in Japan
}

\author{
Kensaku Maejima, Misako Himeno, Ken Komatsu, Yusuke Takinami, Masayoshi Hashimoto, \\ Shuichiro Takahashi, Yasuyuki Yamaji, Kenro Oshima, and Shigetou Namba
}

First to ninth authors: Department of Agricultural and Environmental Biology, Graduate School of Agricultural and Life Sciences, The University of Tokyo, 113-8657, Japan.

Accepted for publication 17 December 2010.

\section{ABSTRACT}

Maejima, K., Himeno, M., Komatsu, K., Takinami, Y., Hashimoto, M., Takahashi, S., Yamaji, Y., Oshima, K. and Namba, S. 2011. Molecular epidemiology of Plum pox virus in Japan. Phytopathology 101:567-574.

For a molecular epidemiological study based on complete genome sequences, 37 Plum pox virus (PPV) isolates were collected from the Kanto region in Japan. Pair-wise analyses revealed that all 37 Japanese isolates belong to the PPV-D strain, with low genetic diversity (less than $0.8 \%$ ). In phylogenetic analysis of the PPV-D strain based on complete nucleotide sequences, the relationships of the PPV-D strain were reconstructed with high resolution: at the global level, the American, Canadian, and Japanese isolates formed their own distinct monophyletic clusters, suggesting that the routes of viral entry into these countries were independent; at the local level, the actual transmission histories of PPV were precisely reconstructed with high bootstrap support. This is the first description of the molecular epidemiology of PPV based on complete genome sequences.
Plum pox virus (PPV), a member of the genus Potyvirus, is the causal agent of sharka disease, one of the most serious diseases of stone fruit trees (Prunus species). To date, seven strains of PPV (D, M, EA, C, Rec, W, and T) have been identified based on their biological, serological, and molecular properties (37). Sharka disease was first reported in Bulgaria in 1932 (1), and it had spread throughout a large part of Europe by the 1980s (8). In the past two decades, PPV-D has been detected with a restricted distribution in South and North America, Africa, and Asia (8). Although a global spread of PPV-D has greatly affected the stone fruit industry, the introduction pathways of PPV-D isolates into these regions remain unclear.

In March 2009, PPV was first detected in commercial Japanese apricot trees (Prunus mume, one of the most popular fruit trees in East Asia including Japan) in the city of Ome, Tokyo, Japan (23). These trees exhibited ringspot and mottle on leaves, color breaking of petals, and occasionally, mild ringspot and malformation on fruits. Sequencing analysis of 243 base pair fragments amplified using PPV-specific primers, P2 and P1 (45), suggested that the PPV isolates belong to the PPV-D strain. However, further deep and wide nucleotide sequence analyses were required for exact strain typing (7), and to confirm whether other strains exist.

In Japan, Japanese apricot is one of the most popular fruit and flowering trees. In addition, other stone fruit trees such as peach, apricot, Japanese plum, and sweet cherry are also grown widely throughout the country. From April to August 2009, a nationwide PPV detection survey was conducted by the Ministry of Agriculture, Forestry, and Fisheries (MAFF) and prefectural governments throughout Japan, in total of about 2,000 representative Prunus growing orchards and parks, which revealed that PPV was already distributed in other regions of Tokyo, and was not restricted to Ome (total of 46 orchards). Unfortunately, PPV was also detected in Kanagawa Prefecture (one orchard in Odawara) and in Ibaraki Prefecture (one orchard in Mito) (Fig. 1). There-

Corresponding author: S. Namba; E-mail address: anamba@mail.ecc.u-tokyo.ac.jp

doi:10.1094/PHYTO-10-10-0280

(C) 2011 The American Phytopathological Society fore, investigations of the diversity and the local spread patterns of PPV were required for effective eradication. In most cases, however, it was difficult to trace the exact transmission pathways of the virus, except in the cases of Kanagawa and Ibaraki, in which the infected trees were grafted with scions from an orchard in Ome, where the occurrence of PPV had already been confirmed.

Studying molecular variability of the virus genome can resolve relationships among virus isolates to reconstruct the history of viral transmission (5). Although a number of studies have used partial viral sequences $(9,20,24)$, analyses based on complete viral genomes can reconstruct more detailed and reliable viral relationships at the global $(27,39)$ and local $(5,33)$ level. As for PPV, however, there is no such epidemiological study based on the complete genome sequence.

In this study, the complete nucleotide sequence of a Japanese isolate of PPV, designated Ou1, was determined, confirming the presence of the D strain in Japan. Moreover, we report the molecular epidemiology of PPV-D at both global and local levels based on 37 newly determined complete genome sequences of Japanese isolates.

\section{MATERIALS AND METHODS}

Sampling and detection. From September 2008 to October 2009, 37 fresh samples of Prunus leaves and petals with typical PPV symptoms were collected from the cities/towns of Ome (16 samples), Akiruno (3 samples), Hachioji (4 samples), Hinode (4 samples), and Okutama (2 samples) in Tokyo; from Mito (3 samples) in Ibaraki Prefecture; and from Odawara (5 samples) in Kanagawa Prefecture. All samples were stored at $-80^{\circ} \mathrm{C}$ until use. PPV infection was confirmed by serological and molecular method. For the serological method, Plum Pox Virus Immunochromato (Nippon Gene, Toyama, Japan) and DAS-ELISA (Bioreba, Basel, Switzerland) were used according to the manufacturers' protocols. For the molecular method, reverse transcriptionPCR (RT-PCR) was carried out with the SuperScript III One-Step RT-PCR System with Platinum Taq (Life Technologies, Carlsbad, CA) using PPV-specific primers, P2 and P1 (45). Each isolate was designated as described in Table 1. 
Sequencing of the genome of Japanese isolates of PPV. For virus genome sequencing, total RNA was extracted from plant tissues using the RNeasy Plant Mini Kit (Qiagen, Hilden, Germany). The entire PPV genome was amplified in three over-

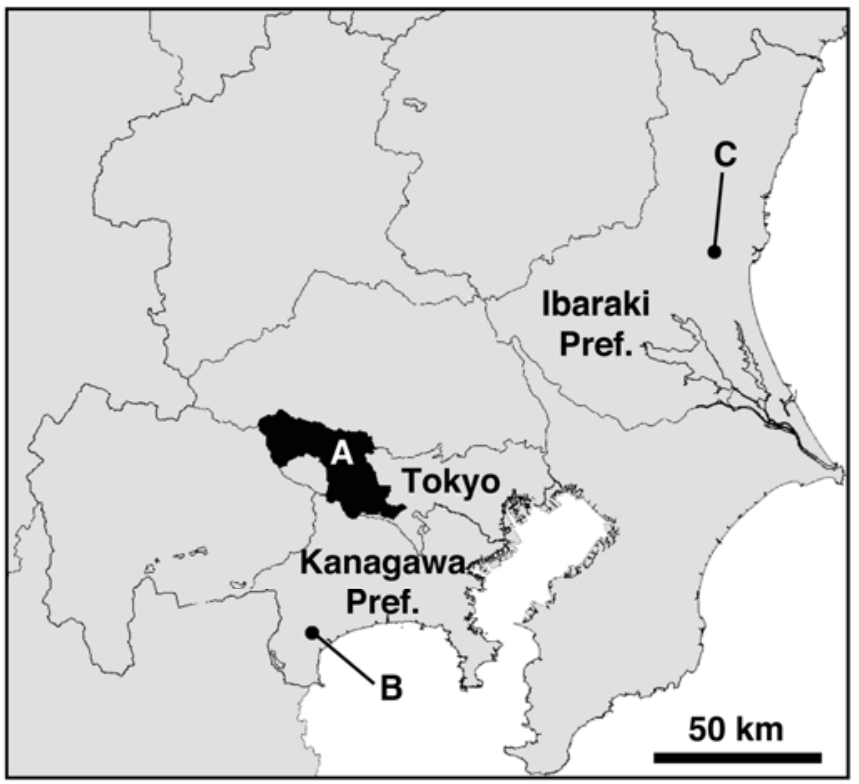

Fig. 1. The distribution map of Plum pox virus in the Kanto region, Japan. A, Ome, Akiruno, Hachioji, Hinode, and Okutama in Tokyo. B, Odawara in Kanagawa Prefecture. C, Mito in Ibaraki Prefecture. lapping fragments using the one-step RT-PCR system described above, with the following three primer sets: PPV1F and PPV3587R, PPV2828F and PPV6683R, and PPV6204F and PPV9786R (Table 2). The amplified products were purified with ExoSAP-IT (GE Healthcare, Buckinghamshire, UK) to remove the unincorporated dNTPs and PCR primers, followed by direct sequencing using an ABI 3130xl genetic analyzer (Life Technologies) with the primers listed in Table 2. The obtained sequences were assembled using ATGC version 4.3.5 software (Genetyx, Tokyo, Japan). For isolate Ou1, 5'- and 3'-terminal sequences were determined using 5'-Full RACE Core Set (Takara Bio, Otsu, Japan) and the GeneRacer kit with AMV RT, TOPO TA Cloning for Sequencing (Life Technologies), respectively, with the primers listed in Table 2. For 36 other Japanese isolates, the 24 nucleotides (nt) at the $5^{\prime}$-end and $26 \mathrm{nt}$ at the $3^{\prime}$-end that formed the primer for RT-PCR amplification were not determined. In the sequence comparison analysis, these undetermined 50 nt were presumed to be conserved among the 37 Japanese isolates, because these regions are completely conserved among foreign PPV-D isolates and Ou1. In the phylogenetic analysis, there was no effect of these undetermined terminal sequences because they were also undetermined in some Canadian isolates, and the complete deletion option for gap was used.

Analyses of the genome sequences of PPV. The sequences were analyzed using the software Genetyx-Mac version 13.1.6 (Genetyx) and MEGA version 4.0 (40). The genetic polymorphism parameters, $\pi$ (29) and $\theta(42)$ values, were calculated using DnaSP version 5.10 (21). Recombination among sequences was analyzed using the RDP (26), GENECONV (30), BOOTSCAN (25), MAXCHI (38), CHIMAERA (32), SISCAN (12), and 3SEQ

TABLE 1. Japanese Plum pox virus isolates used in this study

\begin{tabular}{|c|c|c|c|}
\hline Isolate name $^{\mathrm{a}}$ & Geographic origin & Host plant & GenBank accession no. \\
\hline Ak1 & Akiruno city, Tokyo & Prunus mume cv. Nanko & AB576045 \\
\hline $\mathrm{Ak} 2$ & Akiruno city, Tokyo & P. mume & AB576046 \\
\hline Ak3 & Akiruno city, Tokyo & P. mume & AB576047 \\
\hline $\mathrm{Ha}^{*} *$ & Hachioji city, Tokyo & P. mume & AB576048 \\
\hline $\mathrm{Ha} 2$ & Hachioji city, Tokyo & P. mume & AB576049 \\
\hline $\mathrm{Ha} 3$ & Hachioji city, Tokyo & P. mume & AB576050 \\
\hline $\mathrm{Ha} 4 *$ & Hachioji city, Tokyo & P. mume & AB576051 \\
\hline Hi1** & Hinode town, Tokyo & P. domestica & AB576052 \\
\hline $\mathrm{Hi} 2$ & Hinode town, Tokyo & P. mume cv. Shirokaga & AB576053 \\
\hline $\mathrm{Hi} 3$ & Hinode town, Tokyo & P. mume cv. Nanko & AB576054 \\
\hline $\mathrm{Hi} 4 * *$ & Hinode town, Tokyo & P. mume & AB576055 \\
\hline Ok1 & Okutama town, Tokyo & P. mume & AB576056 \\
\hline $\mathrm{Ok} 2$ & Okutama town, Tokyo & P. mume & AB576057 \\
\hline Ou1*** & Ome city, Tokyo & P. mume cv. Nanko & AB545926 \\
\hline Ou2 & Ome city, Tokyo & P. mume cv. Baigo & AB576058 \\
\hline Ou3 & Ome city, Tokyo & P. mume & AB576059 \\
\hline Ou $4 * * *$ & Ome city, Tokyo & P. mume cv. Nanko & AB576060 \\
\hline Ou5 & Ome city, Tokyo & P. mume & AB576061 \\
\hline Ou6 & Ome city, Tokyo & P. mume & AB576062 \\
\hline Ou 7 & Ome city, Tokyo & P. mume & AB576063 \\
\hline Ou8 & Ome city, Tokyo & P. persica & AB576064 \\
\hline Ou9 & Ome city, Tokyo & P. mume cv. Shirokaga & AB576065 \\
\hline Ou12 & Ome city, Tokyo & P. mume & AB576066 \\
\hline Ou13 & Ome city, Tokyo & P. mume cv. Komukai & AB576067 \\
\hline Ou14**** & Ome city, Tokyo & P. mume cv. Kurenai & AB576068 \\
\hline Ou $15 * * * *$ & Ome city, Tokyo & P. mume cv. Hamachidori & AB576069 \\
\hline Ou16 & Ome city, Tokyo & P. mите & AB576070 \\
\hline Ou17 & Ome city, Tokyo & P. mume & AB576071 \\
\hline Ou18 & Ome city, Tokyo & P. тите & AB576072 \\
\hline $\operatorname{Mi1} * * * * *$ & Mito city, Ibaraki Pref. & P. mume cv. Hamachidori & AB576073 \\
\hline $\operatorname{Mi} 2 * * * * *$ & Mito city, Ibaraki Pref. & P. mume cv. Hamachidori & AB576074 \\
\hline $\operatorname{Mi3} * * * * *$ & Mito city, Ibaraki Pref. & P. mume cv. Hamachidori & AB576075 \\
\hline $\operatorname{Od} 1 * * * * * *$ & Odawara city, Kanagawa Pref. & P. mume cv. Tenjinbai and cv. Kusudama & AB576076 \\
\hline $\operatorname{Od} 2 * * * * * *$ & Odawara city, Kanagawa Pref. & P. mume cv. Kurenai & AB576077 \\
\hline $\operatorname{Od} 3 * * * * * *$ & Odawara city, Kanagawa Pref. & P. mume cv. Shishigashira & AB576078 \\
\hline Od4****** & Odawara city, Kanagawa Pref. & P. mume cv. Mongakushi & AB576079 \\
\hline $\operatorname{Od} 5 * * * * * *$ & Odawara city, Kanagawa Pref. & P. mume cv. Koushuoujuku & AB576080 \\
\hline
\end{tabular}

a Isolates followed by the same number of asterisks were collected from the same orchard (the same block of trees). 
(3) methods implemented in the software RDP3 (18) with default settings. Phylogenetic analysis was performed with the software PhyML version 3.0 (16) using the maximum-likelihood (ML) method under the HKY85 model (17) of sequence evolution. The robustness of the tree topology was confirmed using other algorithms, neighbor-joining (NJ), minimum-evolution (ME), and maximum-parsimony (MP), with the software MEGA version 4.0. The accession numbers and names of the 36 foreign PPV isolates (including all seven strains) used in this study for strain typing and phylogenetic analyses are as follows: PPV-D (AF401295: Penn1, AF401296: Penn2, AY912056: Fantasia, AY912057: Vulcan, AY912058: 48-922, AY953261: Cdn1, AY953262: Cdn3, AY953263: Cdn4, AY953264: Cdn5, AY953265: Cdn7-2, AY953266: Cdn12, AY953267: Cdn123-1, D13751: NAT, DQ465242: Penn3, DQ465243: Penn4, EF640933: Penn5, EF640934: Penn6, EF640935: Penn7, EF640936: Penn8, EF640937: Penn9, EF640938: Penn10, EF640939: Penn12, GU461890: BIII/2, P17767: Rankovic [amino acid sequence data], X16415: Dideron, and X81083: SC); PPV-M (AJ243957: PS, and M92280: SK 68); PPV-EA (AM157175: El Amar, and DQ431465: El Amar); PPV-C (AY184478: SoC, and Y09851: SwC); PPV-Rec (AY028309: BOR-3, and EU117116: J4c); PPV-W (AY912055: W), and PPV-T (EU734794: AbTk).

\section{RESULTS}

Complete nucleotide sequence of a Japanese isolate of PPV, Ou1. To confirm the precise virus strain and molecular property of PPV in Japan, the complete nucleotide sequence of isolate PPV-Ou1 was determined. The genomic RNA of Ou1 was 9,786 nt long, excluding the $3^{\prime}$ terminal poly(A) tail, and contained a single open-reading frame (ORF) (nt 147 to 9569). The ORF encoded a 3,140-amino acid (aa) polyprotein with nine potential potyvirus cleavage sites (36). There was also a putative small
ORF PIPO (nt 2906 to 3217), which is conserved throughout the family Potyviridae (4) and is essential for viral movement (44), in the $P 3$ cistron with a conserved $\mathrm{G}_{2} \mathrm{~A}_{6}$ leading motif (nt 2906 to 2913) at its $5^{\prime}$ end (4).

Next we performed pair-wise comparisons of nucleotide and polyprotein sequences of the Japanese isolate and the 36 other foreign PPV isolates (including all seven strains) described in Materials and Methods, using the software Genetyx-Mac version 13.1.6. Ou1 shared greater sequence identity with the PPV-D isolates throughout its genome ( 98.1 to $99.4 \%$ and 98.2 to $99.6 \%$ at the nucleotide and amino acid levels, respectively) than with the other strains (77.9 to $95.8 \%$ and 88.0 to $97.9 \%$ ). This indicates that Ou1 belongs to the PPV-D strain. Regarding the putative $P I P O$, Oul possessed high sequence identity with the PPV-D isolates (97.4 to $99.7 \%$ and 93.9 to $99.0 \%$ at the nucleotide and amino acid levels, respectively) and with the other strains ( 80.4 to $98.1 \%$ and 71.6 to $94.2 \%$ ).

Sequence properties of PPV in Japan. Immunochromatographic assay kit (PPV immunochromato), DAS-ELISA, and RTPCR were used in the first nationwide detection survey for PPV from April to August 2009, which revealed the geographic distribution of PPV in Japan (Fig. 1). To understand the diversity and relationships of PPV in Japan, 36 further PPV-infected samples collected from these areas were examined by genome sequencing (Table 1). Ou14 and Ou15 were collected from an orchard in Ome, from where scions had been provided to orchards in Odawara and Mito. Viral genomes were amplified from total RNA by one-step RT-PCR, directly sequenced, and assembled. All sequences comprised the complete genome, excluding the $24 \mathrm{nt}$ at the $5^{\prime}$-end and $26 \mathrm{nt}$ at the $3^{\prime}$-end that formed the primer for RT-PCR amplification.

The length of genomic RNA of the 36 isolates was the same as Ou1, with a few exceptions: a single deletion site was identified within the $3^{\prime}$-UTR of Hil and Hi4 isolated from the same orchard

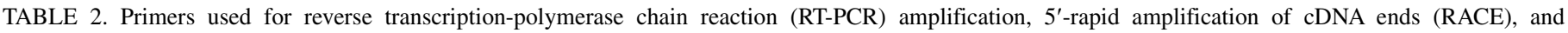
sequencing of the complete Plum pox virus genome in this study

\begin{tabular}{|c|c|c|c|}
\hline Primer name & Sequence $\left(5^{\prime}-3^{\prime}\right)$ & Position & Purpose \\
\hline PPV1F & AAAATATAAAAACTCAACACAACA & $1-24$ & RT-PCR \\
\hline PPV3587R & CACGCCGTCACTTCGCTCCG & $3587-3568$ & RT-PCR and sequence \\
\hline PPV2828F & GAAAGCACGGACGGAATCCG & $2828-2847$ & RT-PCR \\
\hline PPV6683R & TGCGCTTGTTTCCGACATGG & $6683-6664$ & RT-PCR \\
\hline PPV6204F & GAATTGAGGCAGACAGGACACCC & $6204-6226$ & RT-PCR \\
\hline PPV9786R & GTCTCTTGCACAAGAACTATAACCCG & $9786-9761$ & RT-PCR \\
\hline PPV20F & CAACATACAAAATTTTATGCG & $20-40$ & Sequence \\
\hline PPV486F & AGATTCCAATTTCTCAACGG & $486-505$ & Sequence and $5^{\prime}$-RACE \\
\hline PPV528R & TTCGGTTGACTATTGCATCCGG & $528-507$ & Sequence \\
\hline PPV1008F & TCTATTCTTGTCGACTCACGG & $1008-1028$ & Sequence \\
\hline PPV1575F & CGCACGGAGAACATTAGGAGCGG & $1575-1597$ & Sequence \\
\hline PPV1961F & CGAAGATGGTACACCACTGG & $1961-1980$ & Sequence \\
\hline PPV2493F & ATCAGAAGCATTTACAAGCC & $2493-2512$ & Sequence \\
\hline PPV2967F & TTCTCTGCAATCTTGGAATCGCAGCG & $2967-2992$ & Sequence \\
\hline PPV3568F & CGGAGCGAAGTGACGGCGTG & $3568-3587$ & Sequence \\
\hline PPV3971F & AATTGAACCCACCAGGCCGC & $3971-3990$ & Sequence \\
\hline PPV4410F & TATGTCGCAAGTTACAATGAGG & $4410-4431$ & Sequence \\
\hline PPV4936F & CGTTGGTTCGATTTGACGGG & $4936-4955$ & Sequence \\
\hline PPV5588F & TAAGGGGCATTGGAATAAGCG & $5588-5608$ & Sequence \\
\hline PPV6634F & CAAATTTCCAAACGAAGAGC & $6634-6653$ & Sequence \\
\hline PPV6777R & TGCCATCTCGAGTGCTCAC & $6777-6759$ & Sequence \\
\hline PPV7204F & AGAGTGCTCTAAATAAGGACGC & $7204-7225$ & Sequence \\
\hline PPV7684F & GCGTTGGGATGACAAAATTCAGAGGTGG & $7684-8711$ & Sequence \\
\hline PPV8042F & ACACGATTGCATTTGTCGGT & $8042-8061$ & Sequence \\
\hline PPV8602F & AAGTTGATGCAGGCAAGCCG & $8602-8621$ & Sequence \\
\hline PPV8880F & ATTGGAACTTTTACAGTGCCACG & $8880-8902$ & Sequence \\
\hline $\mathrm{P} 2^{\mathrm{a}}$ & CAGACTACAGCCTCGCCAGA & $9337-9356$ & Sequence and 3'-RACE \\
\hline PPV703R & CCATTTGCCTTGGC ${ }^{\mathrm{b}}$ & $703-690$ & $5^{\prime}-\mathrm{RACE}$ \\
\hline PPV431R & GCTTTCTTTGAAGCACCGAAGCC & $431-409$ & 5'-RACE \\
\hline PPV553F & CAGTATGGGTGCCATTCCCTC & $553-573$ & $5^{\prime}$-RACE \\
\hline PPV632F & TAAGGTTAGGATGTCCGAGGC & $632-652$ & 5'-RACE \\
\hline
\end{tabular}

\footnotetext{
a Described by Wetzel et al. (45).
}

b Phosphorylated at the $5^{\prime}$ terminus. 
in Hinode. The nucleotide sequence diversity of the 37 Japanese isolates was very low (maximum [max.] 0.0078, average [avg.] 0.0042), indicating that all isolates belong to the PPV-D strain. This sequence diversity was comparable to those of the American isolates (max. 0.0082, avg. 0.0043) and Canadian isolates (max. 0.0088, avg. 0.0048), but lower than that of European isolates (max. 0.0221, avg. 0.0188). Mixed infection was unlikely because there were only three or less ambiguities per isolate (avg. 0.78 site per isolate), and because there was no discrepancy in the overlapping regions of three separately amplified genomic fragments. No recombination event was also detected in any pair of the Japanese isolates by seven independent programs of the RDP3 software (18). While the $\pi$ values were slightly lower for $6 K 2$ and the nuclear inclusion $b(\mathrm{NIb})$ regions than the other regions, no such differences were noted for the $\theta$ values (Table 3 ). There were 409 variable sites $(4.18 \%)$, of which 131 sites $(1.34 \%)$ were found from more than one isolate (parsimony-informative sites; Pis), and 278 sites $(2.85 \%)$ were from single isolates (Table 3 ). Although the variable sites were evenly distributed throughout the genome, Pis were biased toward some regions, such as the 3 -untranslated region (UTR) (3.23\%), the protein 1 (P1) $(2.16 \%)$, and the nuclear inclusion a proteinase (NIa-Pro) $(2.19 \%)$.

A large single ORF that encodes a polyprotein of 3,140 aa was found in all Japanese isolates. The amino acid sequence diversity of the Japanese isolates was 0.0068 at a maximum (avg. 0.0030), and there were 93 variable sites $(2.96 \%)$. P1 and CP had relatively large number of variable sites $(7.14 \%$ with 22 sites and $5.74 \%$ with 19 sites, respectively), and NIa-Pro had only single amino acid substitution $(0.41 \%)$. The putative protein PIPO was also found, with a diversity of 0.0396 at a maximum (avg. 0.0094), and seven sites of 103 aa were variable. PPV has nine cleavage sites characteristic of potyviruses in its polyprotein (36). Among the Japanese isolates, these sites were mostly the same as those of other foreign PPV isolates, excluding the 6K2/NIa-viral protein genome-linked (VPg) cleavage sites of $\mathrm{Ha} 4$ (EEVVHQ/G $\rightarrow$ DEVVHQ/G). The KITC motif (2) and the PTK motif (31) in the helper component proteinase (HC-Pro), and the DAG motif and its context (22) in $\mathrm{CP}$, which are important for aphid transmission, were conserved among all of the Japanese isolates.

Compared to all deposited foreign PPV-D isolates, we found five nucleotide sites unique to the Japanese isolates, at nt 657, 1598, 2928, 5246, and 7145. Although these were silent at the polyprotein sequence level, the amino acid sequence at nt 2928 was different, unique to the Japanese isolates at codon 8 of PIPO.

Phylogenetic analyses for molecular epidemiology of PPV. To investigate the evolutionary relationships among the Japanese and foreign PPV-D isolates, phylogenetic analyses were performed. Although a number of partial nucleotide sequences of PPV had been deposited to GenBank, we could not obtain reliable trees from these partial sequences, such as the $C P$ region (data not shown). Therefore, a phylogenetic tree was constructed based on 37, 11, 10, and 4 complete genome sequences from Japan, the United States, Canada, and Europe, respectively, using the ML method (Fig. 2). Two PPV-M isolates were used as outgroups. In addition to ML, the NJ, ME, and MP methods were applied, and each gave the same topology as the ML tree, with high bootstrap values (data not shown). The tree showed that the European isolates were richer in diversity than those from the United States, Canada, and Japan as mentioned above, and did not fall into a single cluster. Three European isolates (PPV-BIII/2, PPV-NAT, and PPV-SC) branched close to the root of the tree, and the other European isolate (PPV-Dideron) and the isolates from the United States, Canada, and Japan branched later. The isolates from these non-European regions formed their own well-supported monophyletic clusters.

The Japanese isolates formed two main clades (Fig. 2). Clade A included 27 isolates collected mainly from Ome and its neighboring municipalities (Akiruno, Hinode, and Okutama) in Tokyo (Fig. 3). The isolates from Odawara (Od1-5) and from Mito (Mi1-3) were also included in clade A. This clade was further divided into three subclades (A-I, A-II, and A-III) with high bootstrap support. Subclade A-I included Od1-5, Mi1-3, Ou14, and Ou15. In this subclade, the viruses isolated from mother trees (isolated in Ome: Ou14 and Ou15) were closely related to those from the scions (isolated in Odawara: Od1-5 and Mi1-3); Ou14 and Od2, which had been collected from the same 'Kurenai', and Ou15 and Mi1-3, which had been collected from the same 'Hamachidori', formed clusters with high bootstrap values. Od3 from 'Shishigashira' was included in the cluster of Ou14 and Od2. Subclade A-II consisted of Ou17 and Ou18, which were found in the most eastern areas of Ome. Ou16, which was collected from the northeastern area of Ome, was not included in this subclade. Subclade A-III contained eight isolates from Ome and one each from Akiruno, Hinode, and Okutama. Although these eight Ome isolates were collected from areas close to each other, their relationships were not simple. Ou8 was found about $10 \mathrm{~m}$ from $\mathrm{Ou} 7$, but clustered with a geographically separated isolate, Ok2. Ak2 and Hi3 were positioned outside of the monophyletic cluster of the isolates from Ome and Ok2.

Clade B consisted of ten isolates from the southeastern area where PPV was distributed in Tokyo (Fig. 3). This clade included all isolates from Hachioji. Clade B was further divided into two

TABLE 3. Genome diversity in 37 Japanese isolates of Plum pox virus

\begin{tabular}{|c|c|c|c|c|c|c|c|c|}
\hline \multirow[b]{3}{*}{ Genomic region } & \multicolumn{5}{|c|}{ Nucleotide } & \multirow{2}{*}{\multicolumn{3}{|c|}{$\frac{\text { Protein }}{\text { Variability (\% [number of sites] })}$}} \\
\hline & \multirow[b]{2}{*}{ Size (bp) } & \multicolumn{2}{|c|}{ Polymorphism (per site) } & \multicolumn{2}{|c|}{ Variability (\% [number of sites]) } & & & \\
\hline & & $\pi$ & $\theta$ & Total & $\mathrm{Pis}^{\mathrm{a}}$ & Size (aa) & Total & Pis \\
\hline 5'-UTR & 146 & 0.00624 & 0.01124 & $4.79(7)$ & $1.37(2)$ & - & - & - \\
\hline $\mathrm{P} 1$ & 924 & 0.00607 & 0.01155 & $5.41(50)$ & $2.16(20)$ & 308 & $7.14(22)$ & 3.57 (11) \\
\hline HC-Pro & 1,374 & 0.00515 & 0.00956 & $4.51(62)$ & 1.38 (19) & 458 & $3.28(15)$ & $0.44(2)$ \\
\hline P3 & 1,050 & 0.00366 & 0.00782 & $3.53(37)$ & $1.33(14)$ & 350 & 3.14 (11) & $1.71(6)$ \\
\hline $6 \mathrm{~K} 1$ & 156 & 0.00497 & 0.00658 & $3.21(5)$ & $1.92(3)$ & 52 & $3.85(2)$ & $1.92(1)$ \\
\hline CI & 1,905 & 0.00382 & 0.00862 & $3.94(75)$ & 1.00 (19) & 635 & $1.89(12)$ & $0.31(2)$ \\
\hline $6 \mathrm{~K} 2$ & 159 & 0.00232 & 0.00774 & $3.14(5)$ & 0.63 (1) & 53 & $3.77(2)$ & $0.00(0)$ \\
\hline NIa-VPg & 579 & 0.00395 & 0.00886 & $4.15(24)$ & $1.73(10)$ & 193 & $1.55(3)$ & $1.04(2)$ \\
\hline NIa-Pro & 729 & 0.00467 & 0.00844 & $4.12(30)$ & 2.19 (16) & 243 & $0.41(1)$ & $0.41(1)$ \\
\hline $\mathrm{NIb}$ & 1,554 & 0.00272 & 0.00832 & $3.93(61)$ & $0.58(9)$ & 518 & $1.16(6)$ & 0.19 (1) \\
\hline $\mathrm{CP}$ & 990 & 0.00460 & 0.00992 & $4.43(44)$ & $1.11(11)$ & 330 & $5.74(19)$ & $1.21(4)$ \\
\hline 3'-UTR & 217 & 0.00759 & 0.00950 & $4.61(10)$ & $3.23(7)^{b}$ & - & - & - \\
\hline Total & 9,786 & 0.00429 & 0.00904 & $4.18(409)$ & $1.34(131)$ & 3,140 & $2.96(93)$ & $0.96(30)$ \\
\hline PIPO & 309 & 0.00350 & 0.00592 & $2.59(8)$ & $1.29(4)$ & 103 & $6.80(7)$ & $1.94(2)$ \\
\hline
\end{tabular}

a Parsimony informative sites.

b Including single gap of Ak1 and Ak4. 
subclades B-I and B-II, with high bootstrap support. Subclade B-I included five isolates: two from the same orchard in Ome (Ou1 and $\mathrm{Ou} 4)$, two from the same orchard in Hinode (Hil and Hi4), and one from Hachioji (Ha1). The two pairs from Ome and
Hinode formed their own monophyletic clusters with high bootstrap values. Subclade B-II consisted of the other isolates from Hachioji (Ha2-4). Although Ha1 and Ha4 were also collected from a single orchard, they did not form a single cluster. Overall,

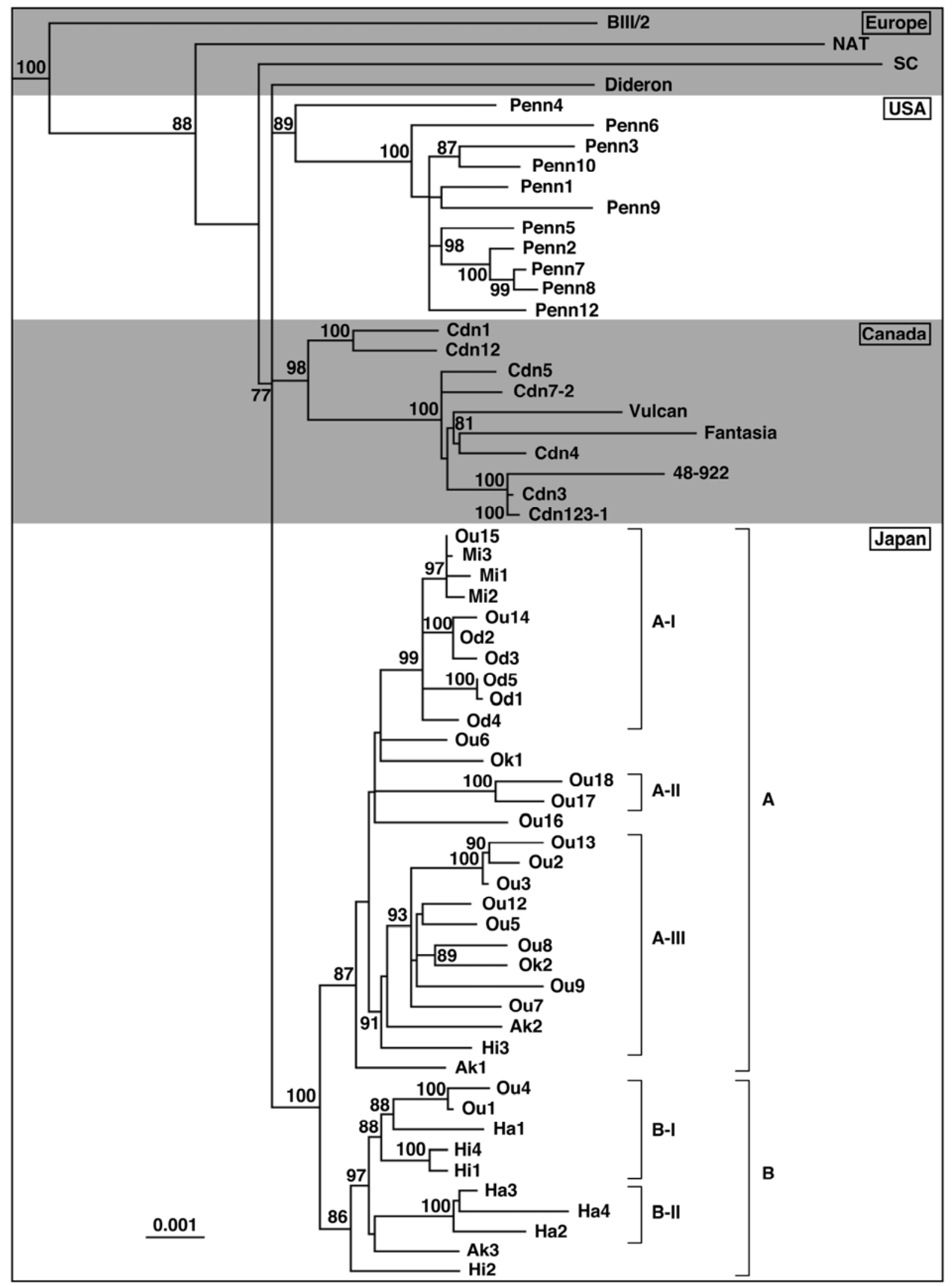

Fig. 2. Maximum-likelihood phylogenetic tree based on complete genome sequences of the Plum pox virus (PPV)-D isolates including the 37 Japanese isolates. Two PPV-M isolates, PS and SK 68 were used to root the tree. Numbers at the nodes represent the percentage of bootstrap values obtained for 1,000 replicates (only values above $75 \%$ are shown). The scale bar indicates the number of nucleotide substitutions per site. 
both of the isolates from Okutama were included in clade A, and all of the isolates from Hachioji were in clade B. The geographic relationships of the isolates from Ome were reflected in the phylogenetic tree to some extent; on the other hand, most of the isolates from Akiruno and Hinode were not phylogenetically closely related and were dispersed into different parts of the cluster of Japanese isolates.

\section{DISCUSSION}

This is the first report on the molecular epidemiology of PPV based on the complete nucleotide sequence. Although the emergence of the PPV-D strain has been reported in South and North America, Africa, and Asia (8), there has not been an investigation of their global and local relationships. This could be because of the low genetic diversity of the PPV-D strain (15), which does not allow precise phylogenetic estimations using partial sequence data, and because of the limited availability of complete genome sequence data. However, from the revealed 37 full-length PPV genome sequences, we constructed a phylogenetic tree supported with high bootstrap values, using several different algorithms, even considering the low genetic diversity of the PPV-D strain (Fig. 2). The accuracy of the tree was supported further by subclade A-I, in which the tree topology agreed well with the actual relationships between scions and their mother trees (Fig. 2). Therefore, our results suggest that complete genome analysis can reconstruct the transmission histories of PPV strains, and improve the precision of epidemiological studies.

Based on the results of this study, all of the Japanese isolates belong to the PPV-D strain, having low genetic diversity. This strain is experimentally transmissible to many Prunus species by aphid inoculation (6). The potyvirus motifs associated with aphid transmission were conserved in the Japanese isolates, indicating the possibility of aphid transmission.

In the Japanese isolates, the variable sites were evenly distributed throughout the genome at the nucleotide level (Table 3). However, there were relatively more variable sites in P1, CP, and PIPO at the amino acid level, while NIa-Pro had only a single amino acid substitution site. The uneven distribution of the variable sites at the amino acid level may be due to differences of their functional targets. P1 and CP are highly variable proteins among potyviruses (36), and may be host-specific determinants of PPV (35,36). PIPO is involved in viral movement (44) by localizing to plasmodesmata using the host secretory pathway (43). On the other hand, NIa-Pro of PPV functions as a proteinase to cleave the conserved sites in viral polyprotein in vitro (11). The variability in $\mathrm{P} 1, \mathrm{CP}$, and PIPO may represent evolutionary adaptation of the Japanese isolates to host plants.

Frequent recombination events between genomic viral RNAs have been reported for potyviruses $(34,41)$, and make precise phylogenetic analyses difficult (41). For PPV, some natural recombination events have been also indicated $(14,28,37)$. On the other hand, among 37 Japanese isolates, neither recombination nor mixed infection was detected. This may indicate that the density of viral distribution in Japan was not so high as to allow mixed infection and genomic recombination. In future studies, however, continuous monitoring of them is required.

In this study, we investigated phylogenetic relationships of the PPV-D isolates on both global and local levels by analyzing PPV full-length genome sequences from Japan (37 isolates), Europe and North America (Fig. 2). Numerous partial nucleotide sequences, such as the $C P$ coding region, are available, but phylo-

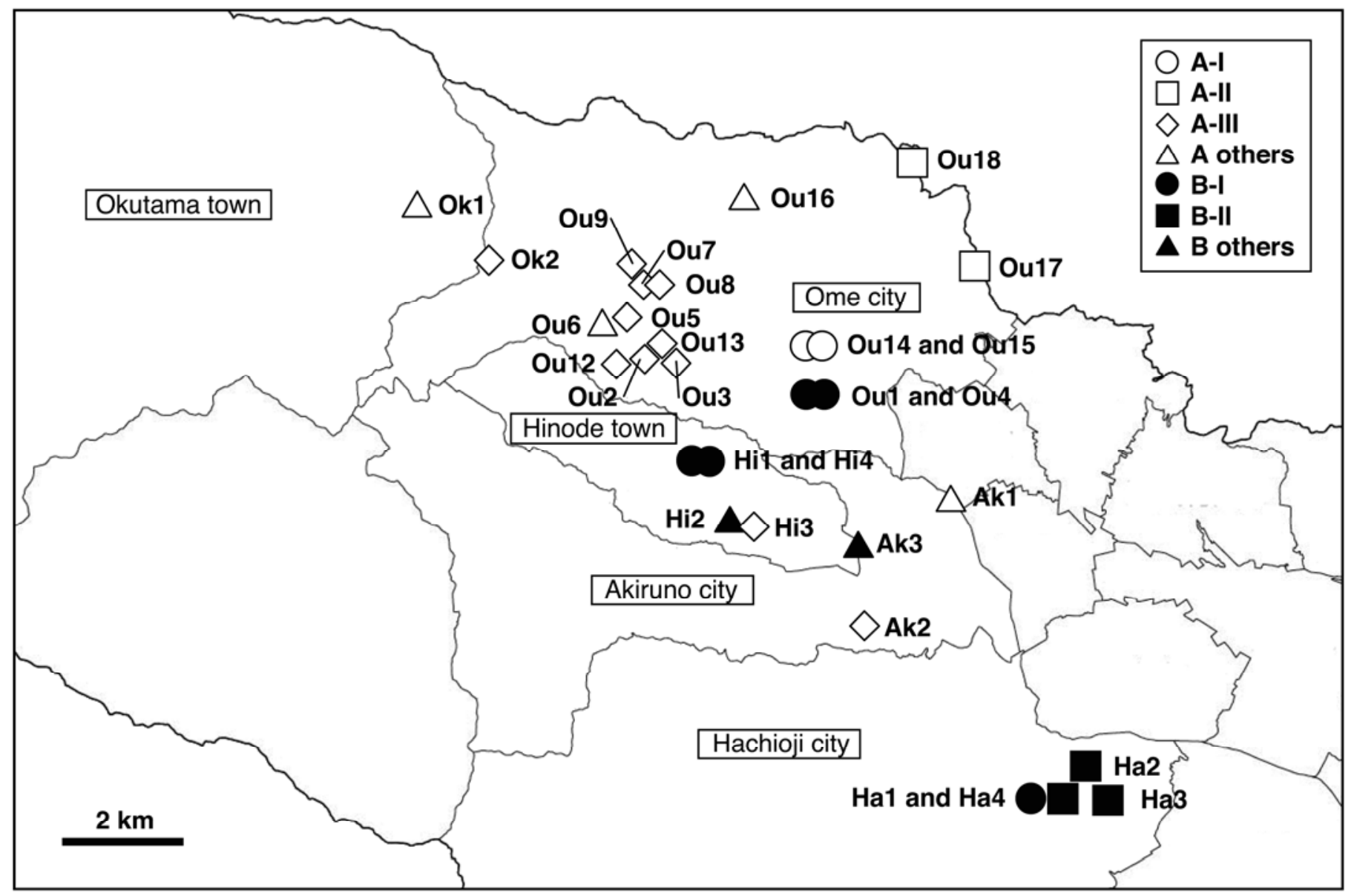

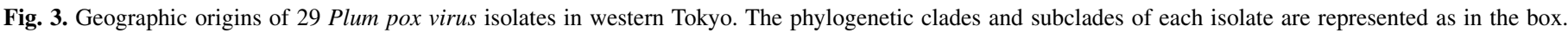
The names of isolates collected from the same orchard (refer to Table 1) are described sequentially (e.g., Ha1 and Ha4). 
genic analysis supported by high bootstrap values is difficult since they represent only part of the genetic diversity $(10,13,14)$, as is also observed in Table 3. Similarly, we were unable to construct reliable phylogenetic trees using partial nucleotide sequences of PPV-D worldwide isolates (data not shown).

Among the seven PPV strains, PPV-D has established a global distribution, but its transmission routes remain unresolved. In our phylogenetic study, isolates from the United States, Canada, and Japan formed well-defined and distinct clusters. This implies that the PPV in Japan is not a descendant of the North American isolates, and that the routes of viral entry into these countries were independent. On the other hand, the phylogenetic variation in the European isolates is indicative of early branching events and high genetic diversity in the PPV-D population in Europe. This is also implied from previous studies $(10,19)$; therefore, our results suggest that PPV may have spread directly or indirectly from its origin in Europe to other regions, including Japan. Our results, however, also confirm the necessity for further genome sequencing of European isolates. Moreover, no information is available about the complete genome sequences of the PPV-D isolates from South American, African, and Asian countries, except for Japan. Further study of these isolates will reveal their relationships with the Japanese isolates, and provide important clues to help understand the global epidemiology of PPV-D. Elucidation of the global transmission routes of PPV is key for the international control of this pathogen.

The local relationships of PPV isolates in Japan were reconstructed with high resolution. In the present study, it was estimated that the PPV isolates in Odawara (Od1-5) and Mito (Mi1-3) were derived from an orchard in Ome. This result was supported by the phylogenetic tree, having high bootstrap values (Fig. 2, subclade A-I). In this subclade, Od3 was included in the cluster of Od2 and Ou14. Interestingly, although Od3 was isolated from a Japanese apricot cultivar Shishigashira in Odawara, we could not find PPV symptoms on the same cultivar in Ome. We also revealed the relationships of the other isolates. Each of the subclades A-II, A-III, and B-II consisted of isolates from the same geographic region, excluding $\mathrm{Ak} 2, \mathrm{Hi} 3$, and Ok2 in subclade AIII. Therefore, in these regions, viral spread can be explained mainly by aphid transmission. It was implied that Ok2 was derived from Ome, while the origins of $\mathrm{Ak} 2$ and $\mathrm{Hi} 3$ remain unclear. On the other hand, subclade B-I consisted of isolates from different geographic regions, which indicates the possibility of transmission by grafting, or alternatively, the existence of many relay points of aphid transmission. Unfortunately, our present analysis does not explain the origins of some isolates from Akiruno and Hinode. To address this, additional surveys and genome sequencing of other isolates are necessary. However, it appears certain that full-genome sequencing will provide a reliable tool for understanding the local epidemiology of PPV.

\section{ACKNOWLEDGMENTS}

This study was supported through a grant from MAFF in Japan. The samples were collected through collaboration with MAFF and Tokyo Metropolitan Agriculture and Forestry Research Center.

\section{LITERATURE CITED}

1. Atanasoff, D. 1932. Plum pox. A new virus disease. Ann. Univ. Sofía Faculty Agric. Silvic. 11:49-69.

2. Blanc, S., Ammar, E. D., Garcia-Lampasona, S., Dolja, V. V., Llave, C., Baker, J., and Pirone, T. P. 1998. Mutations in the potyvirus helper component protein: Effects on interactions with virions and aphid stylets. J. Gen. Virol. 79:3119-3122.

3. Boni, M. F., Posada, D., and Feldman, M. W. 2007. An exact nonparametric method for inferring mosaic structure in sequence triplets. Genetics 176:1035-1047.

4. Chung, B. Y. W., Miller, W. A., Atkins, J. F., and Firth, A. E. 2008. An overlapping essential gene in the Potyviridae. Proc. Natl. Acad. Sci. USA
105:5897-5902.

5. Cottam, E. M., Haydon, D. T., Paton, D. J., Gloster, J., Wilesmith, J. W., Ferris, N. P., Hutchings, G. H., and King, D. P. 2006. Molecular epidemiology of the foot-and-mouth disease virus outbreak in the United Kingdom in 2001. J. Virol. 80:11274-11282.

6. Damsteegt, V. D., Scorza, R., Stone, A. L., Schneider, W. L., Webb, K., Demuth, M., and Gildow, F. E. 2007. Prunus host range of Plum pox virus (PPV) in the United States by aphid and graft inoculation. Plant Dis. 91:18-23.

7. EPPO. 2004. Standard PM 7/32 Plum pox potyvirus. EPPO Bull. 34:247256.

8. EPPO. 2006. Current status of Plum pox virus and sharka disease worldwide. EPPO Bull. 36:205-218.

9. Gadiou, S., Kúdela, O., Ripl, J., Rebenstein, F., Kundu, J. K., and Glasa, M. 2009. An amino acid deletion in Wheat streak mosaic virus capsid protein distinguishes a homogenous group of European isolates and facilitates their specific detection. Plant Dis. 93:1209-1213.

10. Gadiou, S., Šafářová, D., and Navrátil, M. 2008. Genetic variability of Plum pox virus isolates in the Czech Republic. Eur. J. Plant Pathol. 121:513-517.

11. García, J. A., Martín, M. T., Cervera, M. T., and Riechmann, J. L. 1992. Proteolytic processing of the plum pox potyvirus polyprotein by the NIa protease at a novel cleavage site. Virology 188:697-703.

12. Gibbs, M. J., Armstrong, J. S., and Gibbs, A. J. 2000. Sister-Scanning: A Monte Carlo procedure for assessing signals in recombinant sequences. Bioinformatics 16:573-582.

13. Glasa, M., and Candresse, T. 2005. Partial sequence analysis of an atypical Turkish isolate provides further information on the evolutionary history of Plum pox virus (PPV). Virus Res. 108:199-206.

14. Glasa, M., Palkovics, L., Komínek, P., Labonne, G., Pittnerová, S., Kúdela, O., Candresse, T., and Šubr, Z. 2004. Geographically and temporally distant natural recombinant isolates of Plum pox virus (PPV) are genetically very similar and form a unique PPV subgroup. J. Gen. Virol. 85:2671-2681.

15. Glasa, M., Svanella, L., and Candresse, T. 2006. The complete nucleotide sequence of the Plum pox virus El Amar isolate. Arch. Virol. 151:16791682.

16. Guindon, S., and Gascuel, O. 2003. A simple, fast, and accurate algorithm to estimate large phylogenies by maximum likelihood. Syst. Biol. 52:696-704.

17. Hasegawa, M., Kishino, H., and Yano, T. 1985. Dating of human-ape splitting by a molecular clock of mitochondrial DNA. J. Mol. Evol. 22:160-174.

18. Heath, L., van der Walt, E., Varsani, A., and Martin, D. P. 2006. Recombination patterns in aphthoviruses mirror those found in other picornaviruses. J. Virol. 80:11827-11832.

19. Kajic, V., Cerni, S., Krajacic, M., Mikec, I., and Škoric, D. 2008. Molecular typing of Plum pox virus isolates in Croatia. J. Plant Pathol. 90:S1.9-13.

20. Lecoq, H., Wipf-Scheibel, C., Chandeysson, C., Lê Van, A., Fabre, F., and Desbiez, C. 2009. Molecular epidemiology of Zucchini yellow mosaic virus in France: An historical overview. Virus Res. 141:190-200.

21. Librado, P., and Rozas, J. 2009. DnaSP v5: a software for comprehensive analysis of DNA polymorphism data. Bioinformatics 25:1451-1452.

22. López-Moya, J. J., Wang, R. Y., and Pirone, T. P. 1999. Context of the coat protein DAG motif affects potyvirus transmissibility by aphids. J. Gen. Virol. 80:3281-3288.

23. Maejima, K., Hoshi, H., Hashimoto, M., Himeno, M., Kawanishi, T., Komatsu, K., Yamaji, Y., Hamamoto, H., and Namba, S. 2010. First report of plum pox virus infecting Japanese apricot (Prunus mume Sieb. et Zucc.) in Japan. J. Gen. Plant Pathol. 76:229-231.

24. Markov, P. V., Pepin, J., Frost, E., Deslandes, S., Labbé, A. C., and Pybus, O. G. 2009. Phylogeography and molecular epidemiology of hepatitis C virus genotype 2 in Africa. J. Gen. Virol. 90:2086-2096.

25. Martin, D. P., Posada, D., Crandall, K. A., and Williamson, C. 2005. A modified bootscan algorithm for automated identification of recombinant sequences and recombination breakpoints. AIDS Res. Hum. Retroviruses 21:98-102.

26. Martin, D. P., and Rybicki, E. 2000. RDP: Detection of recombination amongst aligned sequences. Bioinformatics 16:562-563.

27. Mohamed, M. H. A., Kumar, S., Paldurai, A., Megahed, M. M., Ghanem, I. A., Lebdah, M. A., and Samal, S. K. 2009. Complete genome sequence of a virulent Newcastle disease virus isolated from an outbreak in chickens in Egypt. Virus Genes 39:234-237.

28. Myrta, A., Varga, A., and James, D. 2006. The complete genome sequence of an El Amar isolate of plum pox virus (PPV) and its phylogenetic relationship to other PPV strains. Arch. Virol. 151:1189-1198.

29. Nei, M. 1987. Molecular Evolutionary Genetics. Columbia University Press, New York.

30. Padidam, M., Sawyer, S., and Fauquet, C. M. 1999. Possible emergence of new geminiviruses by frequent recombination. Virology 265:218-225. 
31. Peng, Y., Kadoury, D., Gal-On, A., Huet, H., Wang, Y., and Raccah, B. 1998. Mutations in the HC-Pro gene of zucchini yellow mosaic potyvirus: Effects on aphid transmission and binding to purified virions. J. Gen. Virol. 79:897-904.

32. Posada, D., and Crandall, K. A. 2001. Evaluation of methods for detecting recombination from DNA sequences: Computer simulations. Proc. Natl. Acad. Sci. USA 98:13757-13762.

33. Pourkarim, M. R., Verbeeck, J., Rahman, M., Animi-Bavil-Olyaee, S., Forier, A. M., Lemey, P., Maes, P., and Ranst, M. V. 2009. Phylogenetic analysis of hepatitis B virus full-length genomes reveals evidence for a large nosocomial outbreak in Belgium. J. Clin. Virol. 46:61-68.

34. Revers, F., Le Gall, O., Candresse, T., Le Romancer, M., and Dunez, J. 1996. Frequent occurrence of recombinant potyvirus isolates. J. Gen. Virol. 77:1953-1965.

35. Salvador, B., Delgadillo, M. O., Sáenz, P., García, J. A., and SimónMateo, C. 2008. Identification of Plum pox virus pathogenicity determinants in herbaceous and woody hosts. Mol. Plant-Microbe Interact. 21:20-29.

36. Salvador, B., García, J. A., and Simón-Mateo, C. 2006. Causal agent of sharka disease: Plum pox virus genome and function of gene products. EPPO Bulletin 36:229-238.

37. Serçe, Ç. U., Candresse, T., Svanella-Dumas, L., Krizbai, L., Gazel, M., and Caglayan, K. 2009. Further characterization of a new recombinant group of Plum pox virus isolates, PPV-T, found in orchards in the Ankara province of Turkey. Virus Res. 142:121-126.
38. Smith, J. M. 1992. Analyzing the mosaic structure of genes. J. Mol. Evol. $34: 126-129$.

39. Sotelo, E., Fernandez-Pinero, J., Llorente, F., Agüero, M., Hoefle, U., Blanco, J. M., and Jiménez-Clavero, M. A. 2009. Characterization of West Nile virus isolates from Spain: New insights into the distinct West Nile virus eco-epidemiology in the Western Mediterranean. Virology 395:289297.

40. Tamura, K., Dudley, J., Nei, M. and Kumar, S. 2007. MEGA4: Molecular Evolutionary Genetics Analysis (MEGA) software version 4.0. Mol. Biol. Evol. 24:1596-1599.

41. Tan, Z., Wada, Y., Chen, J., and Ohshima, K. 2004. Inter- and intralineage recombinants are common in natural populations of Turnip mosaic virus. J. Gen. Virol. 85:2683-2696.

42. Watterson, G. A. 1975. On the number of segregating sites in genetical models without recombination. Theor. Pop. Biol. 7:256-276.

43. Wei, T., Zhang, C., Hong, J., Xiong, R., Kasschau, K. D., Zhou, X., Carrington, J. C., and Wang, A. 2010. Formation of complexes at plasmodesmata for potyvirus intercellular movement is mediated by the viral protein P3N-PIPO. PLoS Pathogens 6:e10000962.

44. Wen, R. H., and Hajimorad, M. R. 2010. Mutational analysis of the putative pipo of soybean mosaic virus suggests disruption of PIPO protein impedes movement. Virology 400:1-7.

45. Wetzel, T., Candresse, T., Ravelonandro, M., and Dunez, J. 1991. A polymerase chain reaction assay adapted to plum pox potyvirus detection. J. Virol. Methods 33:355-365. 